ases as terminal oxidases in the respiration of plants under four heads.

First, polyphenolases are widely distributed throughout plants and are capable of catalysing the oxidation of most naturally occurring phenols ; secondly, enzymes exist in plant tissues which catalyse the reduction of quinones by reduced coenzyme diphosphopyridine nucleotide, and an electron transfer can be visualized as occurring between their substrates and molecular oxygen; thirdly, the respiration of many plant tissues can be stimulated by the addition of small amounts of polyphenol; and fourthly, many substances which act as competitive inhibitors on polyphenolases or inhibit by complexing with the copper of the enzyme also inhibit the respiration of plant tissues.

Although such evidence at first sight seems impressive, if it is examined critically the conclusion cannot be avoided that proof of the participation of polyphenolases in a respiratory chain has still to be produced. Polyphenolases are not found in all plant tissues, and the fact that model respiratory systems can be constructed in vitro is not evidence that they so function in vivo. Many plant tissues, the respiration of which is stimulated by the addition of polyphenols, contain no polyphenolases and, in those tissues which do, stimulation of respiration may be achieved by the addition of substances such as 2-6-dichloroindophenol and by other dyes. Similarly the inhibition of respiration by substances such as $p$-nitrophenol can be seen with other tissues, for example, yeasts, in which no one would suggest that polyphenolases play any part in respiration. The inhibition of respiration by substances such as Dieca may well be due to the inhibition of other enzyme systems, such as those systems involving ascorbic acid oxidase. The case against a polyphenolase system is largely the case for a cytochrome system. It is possible, as H. S. Mason suggests, that the polyphenolases are concerned in the further oxidation, by dehydrogenation or introduction of hydroxyl groups, of simpler phenolic constituents to such complex products as lignin.

Dr. C. Weurman (Central Institute for Nutrition Research, Utrecht) read the fourth and last paper on "The Oxidation of Phenols in Injured Plant Tissues". The situation is one in which the tissue is dead or in a state of rapidly approaching death. Studies of isolated enzymes in vitro are of no help when the complete chaos of the dying cell is the object of study. As one example of the way enzyme systems interact in such a system, phenoloxidases are frequently inactive towards glycosides, and it will therefore be of importance whether or not active glycosidases are present along with phenoloxidases in the complex system. After discussing results which had been obtained with purified enzymes, Dr. Weurman described his own work with enzyme mixtures from potatoes and mushrooms acting on a large number of naturally occurring phenolic glycosides and aglycones. Only very few of the glycosides were not attacked by these enzyme preparations. Dr. Weurman briefly outlined the part played by oxidation of phenols in the development of desirable commercial quality in tea, cocoa, and cider, and invited discussion in greater detail from the experts in those commodities present at the meeting. A written contribution on polyphenols in fruits to the discussion of Dr. Weurman's paper was submitted by Dr. A. C. Hulme (Ditton Laboratory, Kent).

E. C. Bate-SMITH

\section{FITTING THE JOB TO THE WORKER}

$\mathrm{A}$ $\mathrm{N}$ international sominar under the title "Iritting the Job to the Worker", organized by the European Productivity Agency, was hold at Leyden during March 28-April 3. It was attended by about seventy people, from thirteen European and North American countries, comprising physiologists, psychologists, engineers and industrial physicians in about equal numbers; the aim was to bring out what each has to contribute to the scientific study of the industrial worker as he uses his tools and equipment and as he is affected by his immediate environment, and how such knowledge can be applied to the design of machine and work-place either to increase the effectiveness with which the job is done, or to improve the worker's well-being. Welcoming the participants, Dr. Alexander King (deputy director of the European Productivity Agency) said that the Agency is giving increasing attention to the application of the human sciences to industrial problems linked with productivity. This gathering was to provide opportunity for a full and frank exchange of views between scientists from different countries; and it should help the European Productivity Agency to see further action it could take, bringing together as it does employers, trade unionists and scientists.

The nucleus of the seminar was a small team from different countries which had spent two months in the United States to study activity there in the field of industrial physiology and engineering psychology - the field for which the name 'ergonomies' has developed in Britain. Mr. K. F. H. Murrell, of the Department of Psychology at the University of Bristol, speaking of the visit, commented that nearly all the research in the 'human engineering' field appears to have been done in a military context, and to have concerned itself largely with high-stress situations which do not arise in industry ; the effects of long-continued work at normal stresses still await study, and pending this, there may be danger in premature translation of military results to the industrial field. Prof. H. S. Belding (Department of Occupational Health, University of Pittsburgh), who was United States adviser to the team, commented on its impact in stimulating contact in the United States between the different types of scientists. Also they had not previously experienced the three-sided approach by scientists, employers and unions. The problems needing study are very similar in the United States and in Europe; physical stress has been reduced ("the hardest physical effort of the worker is now that of the housewife"), and the lighting of factories has improved tremendously over the past twenty years; but in new factories some jobs are hotter than ever, and noise-exposure is probably increasing.

The seminar divided into two groups for discussion of particular fields, with short notes in advance by participants on relevant work in progress in their own country. One group discussed the physiological assessment of heavy muscular work and heat-stress, and next day turned to the effects of noise, and noiseabatement. A joint contribution from Dr. F. $H$. Bonjer, of the Department of Occupational Medicine at the Netherlands Institute for Preventive Medicine, and Dr. D. van Zuilen, of the T.N.O. Research Institute for Public Health Engineering, showed impressive collaboration between the physiologist 
and the engineer to carry out surveys of the noise at work places and of the hearing-loss of the people there. With equipment in mobile vans, it now takes only ten minutes to obtain the complete frequency-spectrum of a person's hearing-threshold, and it was pointed out that such a curve may contain a deep 'dip' so narrow that it would be overlooked by measurements at octave-spaced spot-frequencies. Two work places with the same total noise-level but different frequency-distributions (for example, cotton spinning and woaving sheds) may cause very different hearing-losses in the course of, say, ten years; so as well as recording total noise-level, it is necessary to analyse the frequency-spectrum. For places where noise fluctuates, they have developed an instrument which analyses the noise by octave bands and integrates automatically the total time (during a one-hour observation period) for which the noiselevel exceeds the first or second of two pre-set levels. Comparable research on the effects of noise is in progress in other countries, including Germany, Sweden and the United States.

'The parallel group was concerned with primarily psychological problems; and it appeared that whereas all the countries represented are doing work on physiulugical problems of interest to industry, competent specialists who can be called enginoering psychologists are more or less confined to Britain and the United States. Besides discussions on engineering psychology, especially design of machine controls, and on motivations and satisfactions arising from the nature of the work itself, a day was given to discussing display of information, clealing both with the study of pointer-and-scale and other display instruments and panels and with information from sources not specially intended as such. Mr. J. Spencer, of University College, London, in outlining the various types of display, referred especially to results from his own research on the best forms of graduation for scales. Discussion emphasized the importance of information 'displayed' other than visually-for example, to the kinesthetic sense of position or (especially) to hearing : every machine or process has characteristie sounds which are used by the operators to know how it is going, though design engineers usually overlook the importance and potentialities of this, and much further study is needed of the properties and capabilities of the different senses as information-channels. Both groups joined for a discussion on anthropometry, physiology and psychology applied to working postures and machine-design, which showed marked variety in the interests developed in different countries. Thus, the relation between machine-dimensions and operator-posture was approached from the engineering point of view by Dr. B. Schulte, of SiemensSchuckert A.G., Germany, and by Mr. B. Hellern, director of the Research Institute of Production Engineering, Oslo. Starting from psychology, researches on the design of machine-controls were described by Mr. R. ( $\dot{x}$. Sell, of the British Iron and Steel Research Association, and Mr. W. T. Singleton, of the British Boot, Shoe and Allied Trades Research Association. Outstanding as an inter-disciplinary exercise was the design of driver's seat and controls for a tractor-mounted hoe developed by the National Institute of Agricultural Engineering, the need being to steer with an accuracy of about half an inch along the line of plants to be hoed; Mr. K. Provins, of the Department of Human Anatomy of the University of Oxford, deseribed the various anatomical and physio- logical considerations taken into account, while discussion brought out possible psychological effects worth study, due to the relative movement of hoe and plants or to the influence of position and colour of chassis-members in building up the driver's visual field.

Training needs in the field of ergonomics were discussed on the last day. In all countries, trained poople are very few. At the Ph.D. level, Prof. S. D. S. Spragg, of the University of Rochester, indicated his training of experimental psychologists; the need is for engineers, physiologists and psycho. logists thoroughly trained in their own disoiplines and with enough knowledge of the other two to collaborate in joint research. The biggest immediate need, however, and one which came out again and again during the whole seminar, is for some simple training in the field of ergonomics for production engineers and designers at the graduate and technologist levels, since straightforward applications of existing knowledge can now lead to big results. Various small-scale but promising beginnings were indicated, notably by Prof. S. Forssman, of the Swedish Employers' Confederation, and by Prof. E. Grandjean, of the Swiss Federal Institute of Technology, Zurich; and the seminar recommended various steps to bring the need and possible courses before universities and colleges of technology.

Altogether the weok was profitable and stimulating, justifying the remark that never before in this field had so well-balanced a group met, from so many countries. An informal committee, with Prof. Grandjean as corresponding secretary, was charged with exploring ways of continuing intermational contact between 'human work' scientists ; and there was every sign that the various participants were going from Luyden with fresh ideas and determination to broaden and intensify research in this field in their own countries.

R. G. Stansfield

\section{INTERNATIONAL STARCH CONVENTION}

$\mathrm{T}$

HE seventh International Starch Conventivil was held at the Coreal Research Station, Detmold, Germany, during April 24-26. Among the two hundred and forty chemists who attended, there were eighty from abroad representing twenty-one countries. The papers which were read to the meeting were divided into three sessions, on research and analysis; starch manufacture; and on starch fractions and derivatives.

Following the actual Convention, a conference was held on April 27, attended by representatives from fifteen countries, for the purpose of discussing the possibility of standardizing the analysis of starch, its derivatives and by-products, on an international level. The meeting decided that this could best be done under the auspices of the International Organization for Standardization and that this body should be approached with the request for the organization of the necessary working committees in the various countries. The meeting then discussed the report of two ad hoc committees, which had already carried out surveys of methods employed for the determination of protein in starch and the assessment of starch qualities.

The first session of the Convention was opened by Prof. M. Samec (Ljubljana, Jugoslavia), who 